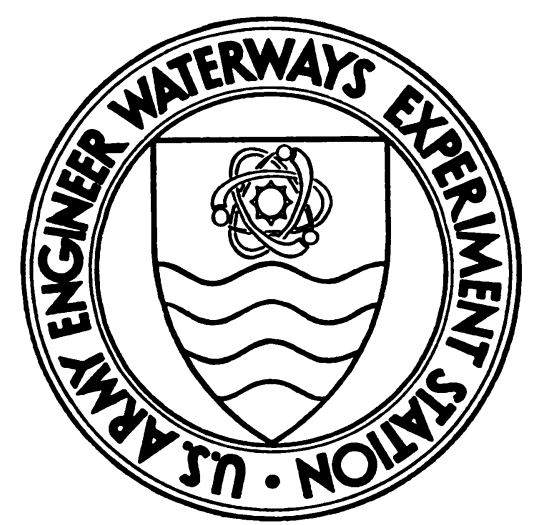

MISCELLANEOUS PAPER M-73-I

\title{
AUTOMATION OF A MODEL FOR PREDICTING SOIL MOISTURE AND SOIL STRENGTH (SMSP MODEL)
}

by

M. H. Smith, M. P. Meyer

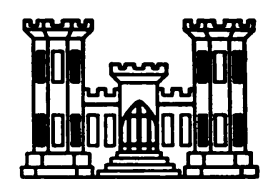

January 1973

Sponsored by U. S. Army Engineer Topographic Laboratories, Fort Belvoir, Virginia Project No. 4A663712D860, Task 04, Work Unit 04

Conducted by U. S. Army Engineer Waterways Experiment Station Mobility and Environmental Systems Laboratory

Vicksburg, Mississippi 